16. C. J. Hollis et al., Geol. Soc. N.Z. Misc. Publ. 108A, 78 (2000).

17. T. Saito, T. Yamanoi, K. Kaiho, Nature 323, 253 (1986).

18. K. R. Johnson, D. J. Nichols, M. Attrep Jr., C. J. Orth, Nature 340, 708 (1989).

19. D. J. Nichols, R. F. Fleming, N. O. Frederiksen., in Extinction Events in Earth History, E. G. Kauffman, O. H. Walliser, Eds. (Springer, New York, 1990), p. 351364.

20. K. O. Pope, K. H. Baines, A. C. Ocampo, B. A. Ivanov, J. Geophys. Res. 102, 21645 (1997).
21. C. J. Hollis, K. A. Rodgers, R. J. Parker, Geology 23, 835 (1995).

22. T. Jones, B. Lim, Palaeogeogr. Palaeoclimatol. Palaeoecol. 164, 57 (2000).

23. A. C. Scott, B. H. Lomax, M. E. Collinson, G. R. Upchurch, D. J. Beerling, Palaeogeogr., Palaeoclimatol. Palaeoecol. 164, 381 (2000).

24. J. A. Wolfe, Nature 352, 420 (1991).

25. W. S. Wolbach, R. S. Lewis, E. Anders, Science 230 167 (1985).

26. W. S. Wolbach, I. Gilmour, E. Anders, C. J. Orth, R. R. Brooks, Nature 334, 665 (1988)
27. D. Heymann et al., Geol. Soc. Am. Spec. Pap. 307, 453 (1996).

28. H. J. Melosh, N. M. Schneider, K. J. Zahnle, D. Latham, Nature 343, 251 (1990)

29. S. D'Hondt, J. King, C. Gibson, Geology 24, 611 (1996).

30. Supported by the New Zealand Marsden Fund, the Swedish Wenner-Gren Foundation, and the Royal Physiographic Society, Sweden. We thank R. Tremain for sample preparation and D. Mildenhall, P. Strong and $\mathrm{L}$. Kennedy for comments on the manuscript.

24 July 2001; accepted 9 October 2001

\title{
Tree Diversity in Tropical Rain Forests: A Validation of the Intermediate Disturbance Hypothesis
}

\author{
Jean-François Molino* and Daniel Sabatier
}

The "intermediate disturbance hypothesis," which postulates maximum diversity at intermediate regimes of disturbance, has never been clearly proved to apply to species-rich tropical forest tree communities and to local-scale canopy disturbances that modify light environments. This hypothesis was tested on a sample of 17,000 trees in a Guianan forest, 10 years after a silvicultural experiment that added to natural treefall gaps a wide range of disturbance intensities. Species richness, standardized to eliminate density effects, peaked at intermediate disturbance levels, particularly when disturbance intensity was estimated through the percentage of stems of strongly light-dependent species.

The proposition that "the highest diversity is maintained at intermediate scales of disturbance" (1), known as the "intermediate disturbance hypothesis," remains largely untested for the highly diverse rain forest tree communities, and for the most prevalent patch-size disturbances (2) in such communities, canopy light gaps (3). This model is particularly difficult to study in this case because (i) trees are longlived, thus, data sets large enough to cover temporal and spatial variations of tree species richness and their relationships with disturbances are very few (4-6), and (ii) the mechanisms through which light gaps influence tree regeneration are still not fully elucidated (3). Until now, most studies have focused on the pioneer guild and early gap phases, and on the pioneer/ nonpioneer and gap/nongap contrasts, because both conceptual objects are rather easily circumscribed in the field: shade-intolerant pioneer species germinate exclusively in open places, and newly opened gaps can be delimited through canopy height measurement (7). These approaches have demonstrated the existence of interspecific differences in light requirements among tropical forest trees, but have given little

Institut de Recherche pour le Développement, c/o Cirad-forêt, Campus International de Baillarguet, TA10/D, 34398 Montpellier Cedex 5, France.

*To whom correspondence should be addressed. Email: molino@mpl.ird.fr evidence of gap partitioning by pioneers (3), thus failing to convince all ecologists that the intermediate disturbance hypothesis could explain the maintenance of high tree species diversity in tropical rain forests.

In a study of the variation in species richness of tree saplings during early gap-phase regeneration in a 50-ha plot at Barro Colorado Island (BCI), Panama, Hubbell et al. concluded that this hypothesis should be rejected in favor of another model, the recruitment limitation hypothesis (8). According to this hypothesis, the effects of dispersal- and recruitment-limitation on tree species diversity outweigh those of disturbance. Although the opening of gaps in mature forest does enlarge the choice of available niches, these would not necessarily be filled by the most adapted species, but rather by those whose propagules are abundant enough at the right place and the right time. The observed increase in species richness with gap size is thus attributed by the authors only to a steep increase in stem density (8).

We tested the intermediate disturbance hypothesis at Paracou, French Guiana [Supplemental fig. $1(9)](10,11)$. We selected ten $20 \mathrm{~m}$ by $250 \mathrm{~m}$ transects, three in untouched control areas and the remainder in seven 9-ha plots commercially logged in 1986-88 (12), associated or not with selective felling of noncommercial trees for fuel and with thinning by poisongirdling (Fig. 1) (10, 11). Through 1995 (transects in control areas) and 1996-97 (other transects), we censused all trees with a dbh (diameter at breast height, or trunk diameter at $1.3 \mathrm{~m}) \geq 2 \mathrm{~cm}$ in our 5-ha study area. All were tagged, mapped, measured, and identified to species (13) (>17,000 stems belonging to 546 species). From former independent studies, we distinguished two nested groups of species: a set of 97 heliophilic (sun-loving) species, including 61 pioneer, strictly gap-dependent species [Supplemental table 2 (9)].

After excluding swampy and seasonally flooded areas ( $8.8 \%$ of total area), we partitioned our transects in $20 \mathrm{~m}$ by $20 \mathrm{~m}$ terra firme quadrats. In each quadrat, we estimated the light-gap disturbance level through lost basal area (LBA) of removed, killed, naturally fallen, or dead trees of $\mathrm{dbh} \geq 10 \mathrm{~cm}$ from 1987 to 1994 , in the $40 \mathrm{~m}$ by $40 \mathrm{~m}$ area in which it was centered. Hereafter, we refer to the cumulated LBA over this 8-year period for each quadrat as its LBA. Of these 99 quadrats, 32 had been crossed by skid trails where logging operations, apart from the opening of canopy light gaps, resulted in increased disturbances of understory and soil. Because such disturbances are not taken into account in LBA as defined above, trail quadrats were excluded from analyses involving this disturbance indicator. LBA varied from 0 to $24.6 \mathrm{~m}^{2} /$ ha (1.94 to $27.2 \mathrm{~m}^{2} /$ ha for trail quadrats).

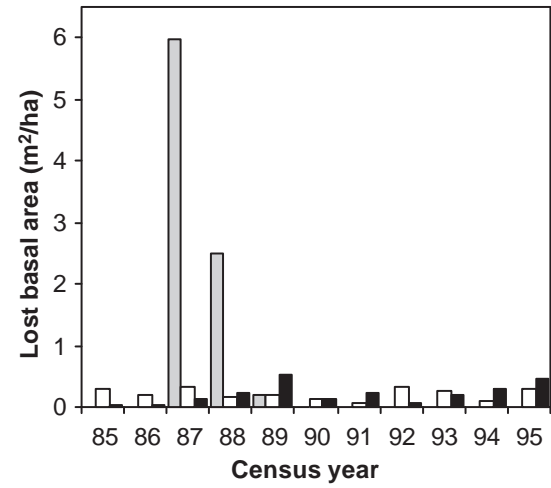

Fig. 1. Annual distribution of disturbances, estimated using $L B A$, in the seven treated transects (3.5 ha) at Paracou between 1985 and 1995. Gray, artificial disturbances; white, natural treefalls; black, standing dead trees. Years are those of censuses: artificial deaths in 1986 were recorded in 1987. Many trees poisoned in 1988 actually died in 1989. 
REPORT S

Fig. 2. Species richness of the 2- to $10-\mathrm{cm} \mathrm{dbh}$ tree communities in the 99 Paracou $400 \mathrm{~m}^{2}$ terra firme quadrats, as a function of the percentage of pioneer stems (\%PS) or heliophilic stems (\%HS) in the same dbh class. Species richness per quadrat $\left[\mathrm{E}\left(\mathrm{S}_{40}\right)\right]$ is calculated using Hurlbert's rarefaction method (15) for a standard sample size $n=40$. (A) $\mathrm{E}\left(\mathrm{S}_{40}\right)$ as a function of \%PS [regression curve: $F(2,96)=36.50, P<0.001]$. (B) $\mathrm{E}\left(\mathrm{S}_{40}\right)$ as a function of $\%$ HS [central regression curve: $F(2,96)=55.86, P<$ 0.001]. Upper and lower curves are regression lines for maxima and minima in steps of $5 \% \mathrm{HS}(n=16)$. (C) Same as (B), but quadrats in five classes. Classes 1 through $4=$ nontrail quadrats. Class 1 (LBA $<2 \mathrm{~m}^{2} / \mathrm{ha}$ ): solid diamonds, unbroken bold regression line $[F(1,16)=11.93, P<0.005]$. Class $2\left(2 \mathrm{~m}^{2} /\right.$ ha $\leq \mathrm{LBA}<$ $4.5 \mathrm{~m}^{2} / \mathrm{ha}$ ): open triangles, medium-dashed bold line $[F(1,15)=3.98$,

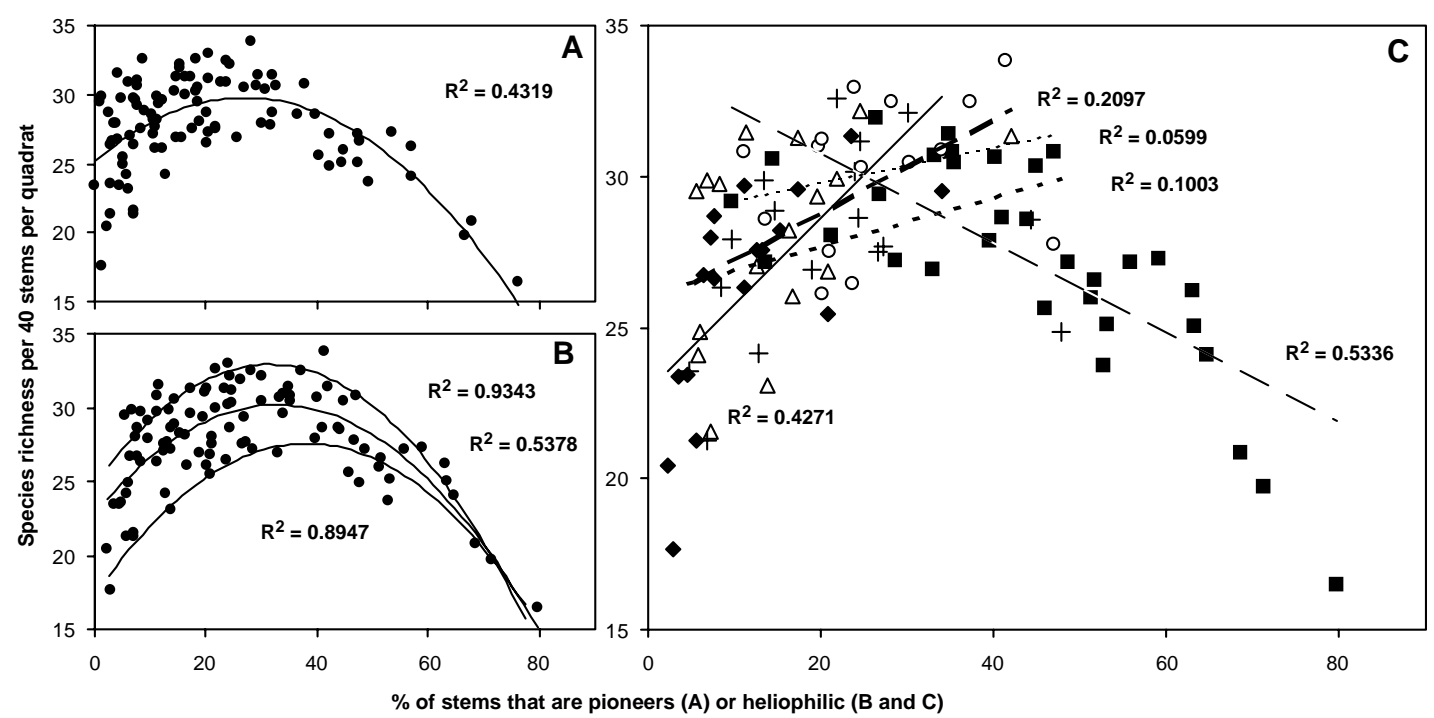

N.S.]. Class $3\left(4.5 \mathrm{~m}^{2} / \mathrm{ha} \leq \mathrm{LBA} \leq 12 \mathrm{~m}^{2} / \mathrm{ha}\right)$ : crosses, long-dashed line $\left[F(1,15)=1.67\right.$, N.S.]. Class $4\left(\right.$ LBA $\left.>12 \mathrm{~m}^{2} / \mathrm{ha}\right)$ : open circles, shortdashed bold line $[F(1,13)=0.83$, N.S.]. Class $5=$ trail quadrats: solid squares, unbroken light line $[F(1,30)=34.32, P<0.001]$.

We analyzed stem density, species richness, and composition of the 2- to $10-\mathrm{cm}$ dbh tree communities [see supplemental methods (9)] in the 99 terra firme quadrats. As expected from other studies, stem density was highly variable, from 44 to 236 per quadrat, and positively influenced by LBA $\left[r^{2}=0.411, F(1,65)=45.31\right.$, $P<0.001]$. It was also lower in nontrail than in trail quadrats (104 versus 144 stems/quadrat, $P$ $\ll 0.001$, Mann-Whitney U test). LBA increase had a similar positive impact on the percentages of pioneer and heliophilic stems (\%PS, \%HS): $r^{2}=0.254, F(1,65)=22.10$ and $r^{2}=0.294$, $F(1,65)=27.06$, respectively; $P<0.001$ in both cases. LBA, stem density, \%PS, and \%HS did not vary with topography: Kruskal-Wallis test of comparison among three topography classes of nontrail quadrats (lowlands, slopes, and hilltops) gave $P$ values of $0.11,0.50,0.44$, and 0.27 , respectively, for the four parameters.

We tested for an effect of LBA on species richness in nontrail terra firme quadrats. To avoid the effects of the "species per stem paradox" (14) arising from variations in stem density, we applied Hurlbert's rarefaction method to calculate $\mathrm{E}\left(\mathrm{S}_{n}\right)$, "the expected number of species in a sample of $n$ individuals selected at random" (15) among all trees encountered in each quadrat. We fixed $n$ to 40 , the maximum value that permitted calculation of $\mathrm{E}\left(\mathrm{S}_{n}\right)$ for all quadrats. Although $\mathrm{E}\left(\mathrm{S}_{40}\right)$ did not vary among the three topography classes $(P=0.29)$, we found that $16.02 \%$ of its total variance was explained by LBA $[F(1,65)=12.4, P<$ $0.001]$. Despite the relatively low precision of our estimator, this result supports the hypothesis that disturbance had a significant effect on species richness.

For better accuracy in the analysis of the relationship between disturbance and species

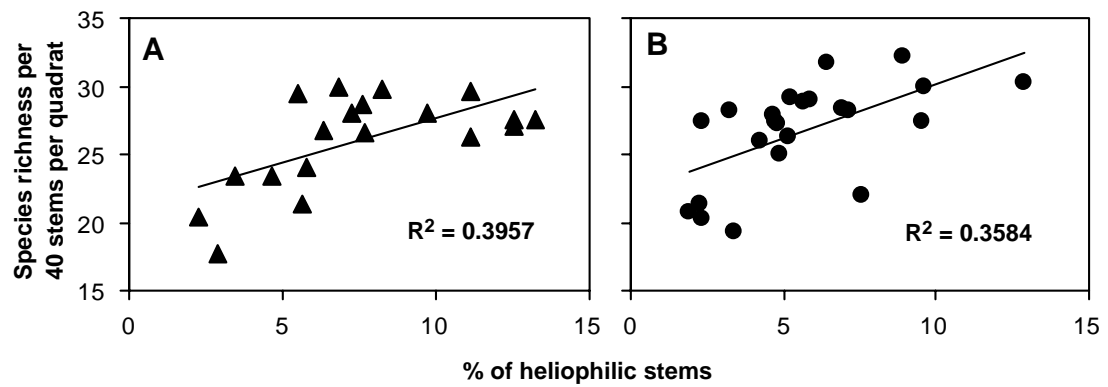

Fig. 3. Species richness per $400 \mathrm{~m}^{2}$ terra firme quadrat (see text and Fig. 2) as a function of the percentage of heliophilic stems (\%HS) in control forests, in the 2- to $10-\mathrm{cm}$ dbh tree communities. Regression lines are calculated on quadrats having \%HS $<15 \%$. (A) Paracou, 19 quadrats ( $0.76 \mathrm{ha})$ in control transects $[F(1,17)=11.13, P<0.005]$. (B) PSE, 23 quadrats, 0.92 ha $[F(1,21)=11.73$, $P<0.005]$.

richness, we used other indicators of disturbance, the \%PS and \%HS in the 2- to $10-\mathrm{cm}$ dbh class. Because pioneer species establish only in gaps, their occurrence and density should record the recent history of canopy gap openings. Heliophilic stems (including pioneers) should not only reflect more precisely treefall gaps, but also smaller and/or slighter disturbances that increase the amount of light reaching the forest floor. Here, as expected from the intermediate disturbance hypothesis, we found a significant humpbacked relationship between both indicators and species richness (Fig. 2, A and B) (16). This relationship was stronger for \%HS than for $\% \mathrm{PS}$, mostly because the former, being more sensitive to low disturbance levels, improved the perception of intermediate disturbance phenomena. Interestingly, when quadrats were partitioned into classes according to their LBA, the relationships between $\% \mathrm{HS}$ and $\mathrm{E}\left(\mathrm{S}_{40}\right)$, both within and among classes, were consistent with the intermediate disturbance hypothesis: note the ordered slopes of the various regression lines in Fig. 2C.

Would this result apply to natural forests? To answer this question, we tested the relationship between $\mathrm{E}\left(\mathrm{S}_{40}\right)$ and \%HS on a subset of data limited to the three transects in control plots, and on the same kind of census data (17) from 1.04 ha of untouched rain forest at Piste de St Elie (PSE), about $15 \mathrm{~km}$ distant from Paracou [Supplemental fig. 1 (9)]. The significant increase at both sites of species richness from 0 to $15 \% \mathrm{HS}$ (corresponding to the ascending part of the curve in Fig. 2B) is contrary to the prediction $(8)$ that, in tropical forests, recruitment limitation would decouple the control of species richness from disturbance regime (Fig. 3). We account for this contrast of conclusions as follows.

Based on the comparison of similar sampling areas $(500 \mathrm{~m}$ by $1000 \mathrm{~m})$, it appears that the Paracou-PSE forest is much more speciesrich than the BCI forest [Supplemental table 1 (9)]. The late successional, shade-loving forests of the Guianas (18) might also be less rich in 
heliophilic species than are Central American forests, because the latter suffer more frequent large disturbance events such as severe droughts (19). Thus, the flora of BCI, apart from evident biogeographical differences, would have undergone a shift toward heliophily through a more intensive long-term disturbance regime (20), and the BCI tree community might have reached a higher degree of species evenness, a situation where any further disturbance could only decrease local species richness, and where recruitment limitation would necessarily play a major role.

Most gap-oriented studies exclude a notable part of the "light level or canopy closure continuum that extends into progressively shadier conditions well beyond the absence of recognizable openings in the forest canopy" $(21,22)$. However, this shadier part of the light gradient is also the result of disturbances: even when they do not result in true canopy opening, the falls of small trees or broken branches modify understory and subcanopy structure, and thus permeability to light. The use of the percentage of heliophilic species as an integrative indirect estimator allowed us to cover the whole range of canopy disturbances in naturally and experimentally disturbed forests.

A premise of the gap paradigm is that the disturbance regime should control species richness exclusively through niche partitioning in recent gaps. However, treefall gaps change the amount and quality of light in the understory not only for a few years, but also for decades after the initial opening. For BCI, Hubbell et al. found that "species richness is established very early during gap-phase regeneration." Most tree species of the Guianan forests, many of them locally rare, are more or less shade-tolerant (18, 23) and might establish through all phases of gap regeneration. Consequently, species richness is likely to change during mid- and late successional stages as well as very early. The use of a large dbh class allowed us to take into account the cumulative effects of disturbances over a 10 -year period.

Hubbell et al. (8) clearly showed that recruitment limitation is an important phenomenon in the BCI forest tree community. Whereas this is probably true in most tropical rain forests, recruitment limitation does not preclude disturbance regime as a cause of variation in species richness. Our results suggest that $\% \mathrm{HS}$ can account for more subtle variations in disturbance regimes than the crude measure of recent treefall gaps, and that the intermediate disturbance hypothesis remains a valid explanation for high species diversity in tropical forest trees.

References and Notes

1. J. H. Connell, Science 199, 1302 (1978)

2. E. van der Maarel, J. Veget. Science 4, 733 (1993).

3. For a recent review, see N. L. Brokaw, R. T. Busing, Trends Ecol. Evol. 15, 183 (2000).
4. A. H. Gentry, Ed., Four Neotropical Rainforests (Yale Univ. Press, New Haven, CT, 1990).

5. R. Condit, Trends Ecol. Evol. 10, 18 (1995).

6. R. Condit et al., J. Ecol. 84, 549 (1996).

7. N. V. L. Brokaw, Biotropica 14, 158 (1982).

8. S. P. Hubbell et al., Science 283, 554 (1999).

9. Supplementary material is available at www. sciencemag.org/cgi/content/full/294/5547/1702/ DC1.

10. L. Schmitt, M. Bariteau, Bois For. Trop. 220, 3 (1990).

11. S. Gourlet-Fleury, F. Houllier, For. Ecol. Manag. 131, 269 (2000).

12. Between October 1986 and January 1988.

13. Trees of $\mathrm{dbh}$ ( $>2800$ stems) are monitored yearly. Data are stored in Cirad-forêt's database. We completed them with our own identifications to species.

14. R. L. Chazdon, R. K. Colwell, J. S. Denslow, Science 285, 1459a (1999).

15. S. H. Hurlbert, Ecology 52, 577 (1971).

16. The pertinency of the use of $\% \mathrm{HS}$ and \%PS as disturbance indicators obviously rests on adequate definitions of pioneer and heliophilic species, within a given biogeographical context. For the present study, the reliability of our classification [documented in Supplemental table 2 (9)] and the relevance of both estimators are attested by various tests that we carried out on the Paracou dataset [Supplemental figs. 2 to 6 (9)].

17. In 1994 , a $20 \mathrm{~m}$ by $500 \mathrm{~m}$ transect and a $20 \mathrm{~m}$ by $20 \mathrm{~m}, 100-\mathrm{m}$ apart plot were inventoried for all trees of $\mathrm{dbh} \geq 2 \mathrm{~cm}$. This resulted in 3050 stems ( 2384 of $\mathrm{dbh}<10 \mathrm{~cm}$ ) in 372 species, including 28 pioneer and 55 heliophilic species. The terra firme areas were partitioned into 25 nonoverlapping $20 \mathrm{~m}$ by $20 \mathrm{~m}$ quadrats.

18. These forests are rich in species with characters reflecting shade tolerance and preference for low levels of disturbance: large seeds, dense wood, and long lifespan (23).

19. R. Condit, S. P. Hubbell, R. B. Foster, J. Trop. Ecol. 12, 231 (1996).

20. This postulation is akin to that of J. S. Denslow, Oecologia 46, 18 (1980) [but see $(24,25)$ ].

21. M. Lieberman, D. Lieberman, R. Peralta, Ecology 70 550 (1989).

22. C. D. Canham, Ecology 70, 548 (1989).

23. H. ter Steege et al., J. Trop. Ecol. 16, 801 (2000).

24. T. C. Whitmore, Biotropica 16, 239 (1984).

25. J. S. Denslow, Biotropica 16, 240 (1984).

26. We thank D. Betian, W. Betian, and O. Ngwete for assistance in fieldwork, Cirad-forêt for the use of Paracou database, L. Allorge, B. Holst, P. Maas, S. Mori, O. Poncy, M.-F. Prévost for identifying numerous sterile botanical vouchers, and D. McKey, S. Mori, F. Hallé, M.-F. Prévost, S. Gourlet-Fleury, H. Dessard, and G. Michaloud for valuable comments. This research was granted by the French Ministry of Environment (SOFT Program-GIP ECOFOR)

28 February 2001; accepted 17 September 2001

\title{
Identification of Ubiquitin Ligases Required for Skeletal Muscle Atrophy
}

\author{
Sue C. Bodine, ${ }^{1}$ Esther Latres, ${ }^{1}$ Susanne Baumhueter, ${ }^{2}$ \\ Venus K.-M. Lai, ${ }^{1}$ Lorna Nunez, ${ }^{1}$ Brian A. Clarke, ${ }^{1}$ \\ William T. Poueymirou, ${ }^{1}$ Frank J. Panaro, ${ }^{1}$ Erqian Na, ${ }^{1}$ \\ Kumar Dharmarajan, ${ }^{1}$ Zhen-Qiang Pan, ${ }^{3}$ David M. Valenzuela, ${ }^{1}$ \\ Thomas M. DeChiara, ${ }^{1}$ Trevor N. Stitt, ${ }^{1}$ George D. Yancopoulos, ${ }^{1}$ \\ David J. Glass ${ }^{1 *}$
}

\begin{abstract}
Skeletal muscle adapts to decreases in activity and load by undergoing atrophy. To identify candidate molecular mediators of muscle atrophy, we performed transcript profiling. Although many genes were up-regulated in a single rat model of atrophy, only a small subset was universal in all atrophy models. Two of these genes encode ubiquitin ligases: Muscle RING Finger 1 (MuRF1), and a gene we designate Muscle Atrophy F-box (MAFbx), the latter being a member of the SCF family of E3 ubiquitin ligases. Overexpression of MAFbx in myotubes produced atrophy, whereas mice deficient in either MAFbx or MuRF1 were found to be resistant to atrophy. These proteins are potential drug targets for the treatment of muscle atrophy.
\end{abstract}

Muscle atrophy occurs as a consequence of denervation, injury, joint immobilization, bed rest, glucocorticoid treatment, sepsis, cancer, and aging (1). Unfortunately, there

${ }^{1}$ Regeneron Pharmaceuticals, 777 Old Saw Mill River Road, Tarrytown, NY, 10591-6707, USA. ${ }^{2}$ Applied Biosystems, 850 Lincoln Center Drive, Foster City, CA 94404, USA. ${ }^{3}$ Derald H. Ruttenberg Cancer Center, Mount Sinai School of Medicine, New York, NY, 10029-6574, USA.

*To whom correspondence should be addressed. Email: david.glass@regeneron.com are no effective treatments for muscle atrophy. The maintenance of muscle mass is controlled by a balance between protein synthesis and protein degradation pathways, which is thought to shift toward protein degradation during atrophy (1). Recently, a signaling pathway that increases protein synthesis was shown to promote muscle hypertrophy, thereby overcoming muscle atrophy $(2,3)$. Although protein degradation systems have been extensively studied, specific molecular mediators of at- 